\title{
Gastrointestinal helminths of Risso's dolphin Grampus griseus from the Western Mediterranean
}

\author{
Mercedes Fernández*, Celia Agustí, F. Javier Aznar, J. Antonio Raga \\ Unidad de Zoología Marina, Instituto Cavanilles de Biodiversidad y Biología Evolutiva, Universidad de Valencia, PO Box 22085, \\ Valencia 46071, Spain
}

\begin{abstract}
The gastrointestinal helminth fauna of 17 Risso's dolphins Grampus griseus (Cuvier, 1812) from the Western Mediterranean was analysed. Five helminth species were found. Adults and juveniles of Hadwenius delamurei were collected from the duodenum of 7 animals. Adults were located significantly more anteriorly than juveniles, which is compatible with a previous hypothesis that species of Hadwenius undergo an ontogenetic migration towards the anterior duodenum. Eggs from Pholeter gastrophilus appeared in 1 small cyst in the main stomach. Adults of Tetrabothrius forsteri and Trigonocotyle globicephalae were collected from the duodenum of 1 and 4 individuals, respectively. Metacestodes, Scolex pleuronectis, were found in the liver, pancreas, pyloric stomach and intestine of 13 individuals. The most favored locations were in the mucosa of the terminal colon and in anal crypts. It is likely that worms select these locations to reach the mesenteries and blubber of the anogenital area, where $S$. pleuronectis might become Monorygma and/or Phyllobothrium. Two individuals of Stenurus globicephalae occurred in the intestine of 1 individual, and were probably swallowed accidentally. The intestinal helminth communities of Risso's dolphin are depauperate. The parasite species found also occur in other oceanic cetaceans from the Western Mediterranean. However, H. delamurei and T. globicephalae are only shared with pilot whales Globicephala spp., which are phylogenetically closely related to Risso's dolphins.
\end{abstract}

KEY WORDS: Risso's dolphin - Grampus griseus · Mediterranean · Hadwenius delamurei - Trigonocotyle globicephalae Tetrabothrius forsteri $\cdot$ Pholeter gastrophilus $\cdot$ Scolex pleuronectis

Resale or republication not permitted without written consent of the publisher

Risso's dolphin Grampus griseus (Cuvier, 1812) is a cetacean species distributed worldwide in temperate and tropical oceans. Few specimens of Risso's dolphin have been available for parasitological analysis because of the offshore habits of this species and the rarity of mass strandings and captures in whaling operations (Baird 2002). The limited information about gastrointestinal helminths comes from samples of 1 to 3 dolphins stranded mainly in the North Atlantic and North Pacific (Zam et al. 1971, Dailey \& Stroud 1978, Shults et al. 1982, Kikuchi et al. 1988, Abollo et al. 1998, Mignucci-Giannoni et al. 1998). In this study we present new data on the helminth fauna of the liver, pancreas, and gastrointestinal tract of 17 Risso's dolphins collected in the Western Mediterranean over the last decades.

Materials and methods. Seventeen Risso's dolphins (10 females and 7 males) that stranded along the Valencian coasts $\left(37^{\circ} 50^{\prime} \mathrm{N}, 0^{\circ} 46^{\prime} \mathrm{E}\right.$ to $\left.40^{\circ} 32^{\prime} \mathrm{N}, 0^{\circ} 30^{\prime} \mathrm{E}\right)$, Spain, from 1989 to 2003 were analysed for parasites. All animals were in good condition (Code 2 sensu Geraci \& Lounsbury 1993), except 1 individual that was decomposed, but with the organs basically intact (Code 3). Body length ranged from 136 to $308 \mathrm{~cm}$ (mean \pm SD: $253 \pm 58$ ); 4 individuals were calves (length $<173 \mathrm{~cm}$ ). The stomach of 17 individuals, the intestine and liver of 16 individuals, and the pancreas of 12 individuals were available for examination, and were stored in a freezer. After thawing, the contents of the forestomach, main stomach, connecting channel and pyloric stomach, and duodenal ampulla were flushed through a sieve (0.2 mm mesh), the solid contents being collected in a Petri dish and examined separately with a stereomicroscope. Each intestine was divided into 20 sections of equal length and the contents of each section were examined using the same procedure. Mean length $( \pm \mathrm{SD})$ of sections was $97 \pm 22 \mathrm{~cm}$. The wall of the stomach and intestines were carefully examined for the presence of ulcers, cysts, and burrowing parasites. Hepatic and pancreatic ducts were opened and examined with a stereomicroscope. The liver and pancreas were then sliced and washed on the sieve to collect parasite specimens that may have been overlooked. Parasites were washed in physiological saline and fixed and preserved in $70 \%$ ethanol. Gastric ulcers were preserved in buffered formalin. Digeneans 
and adult cestodes were stained with iron acetocarmine (Georgiev et al. 1986). Nematodes and metacestodes were cleared in lactophenol. Ecological terminology follows Bush et al. (1997). The description of linear habitat selection by Hadwenius delamurei follows procedures used by Aznar et al. (1997). Vouchers are deposited at the Natural History Museum (NHM) of London, UK, with the following accession numbers: Hadwenius delamurei 2003.1.17.13-14, Trigonocotyle lobicephalae 2003.1.17.12, Scolex pleuronectis 2003.1.17.9-11.

Results and discussion. Except for the 4 calves, all dolphins were infected with at least 1 parasite species. Five helminth species were found. Infection parameters are shown in Table 1. Specimens of Hadwenius delamurei were found in 7 dolphins. Four dolphins harboured only gravid worms (Stage 4 sensu Aznar et al. 1997), with intensities of infection of 21, 3, 3 and 1 worm(s), and 3 dolphins harboured only fully immature individuals with no gonads (Stage 1), with intensities of 2, 2 and 1 worm(s). Aznar et al. (1997) suggested that species of Hadwenius may undergo an ontogenetic migration from the posterior duodenum to the anterior duodenum. A key observation for this hypothesis is that the developmental stages are linearly ordered along the digestive tract, i.e. adult worms are located significantly more anteriorly than immature worms. Data from H. delamurei in Risso's dolphin conforms to this pattern. Considering the beginning of the first intestinal section as Point 0 , the average $( \pm \mathrm{SD})$ position of the median worm of the distribution of Stage 4 worms is $1.3 \pm 0.9$, whereas the position of the median worm of Stage 1 worms is $5.2 \pm 0.6$ (see Aznar et al. 1997 for methodological details). The position of Stage 1 worms is significantly more posterior than that of Stage 4 worms (Mann-Whitney $U$-test, $U=0, \mathrm{n}=7$,

Table 1. Grampus griseus. Prevalence, mean abundance and mean intensity of infection of helminth species found in Risso's dolphins in the Western Mediterranean. $\mathrm{Na}$ : number of hosts analyzed; $\mathrm{Ni}$ : number of hosts infected;

*: only eggs were found within a cyst; + : not counted; DA: duodenal ampulla; I: intestine; L: liver; P: pancreas; PS: pyloric stomach

\begin{tabular}{|lccc|}
\hline Helminth species & $\begin{array}{c}\text { Ni/Na } \\
\text { (prevalence } \%)\end{array}$ & $\begin{array}{c}\text { Abundance } \\
\text { (mean } \pm \text { SD) }\end{array}$ & $\begin{array}{c}\text { Intensity } \\
\text { (mean } \pm \text { SD) }\end{array}$ \\
\hline Digenea & & & \\
Hadwenius delamurei & $7 / 16(43.8)$ & $2.1 \pm 5.2$ & $4.7 \pm 7.2$ \\
Pholeter gastrophilus & $1 / 17(5.9)$ & $*^{*}$ & - \\
Cestoda & & & \\
Trigonocotyle globicephalae & $4 / 16(25)$ & $0.6 \pm 1.7$ & $2.5 \pm 3$ \\
Tetrabothrius forsteri & $1 / 16(6.3)$ & - & - \\
Scolex pleuronectis (L) & $6 / 16(37.5)$ & $8.1 \pm 17.2$ & $21.5 \pm 23.2$ \\
Scolex pleuronectis (P) & $2 / 12(16.7)$ & $1 \pm 0.0$ & $0.2 \pm 0.4$ \\
Scolex pleuronectis (PS, DA) & $4 / 8(50)$ & + & - \\
Scolex pleuronectis (I) & $10 / 16(62.5)$ & - & - \\
\hline
\end{tabular}

1-tailed $\mathrm{p}<0.03)$. The only species of Hadwenius recorded thus far in Risso's dolphin is H. tursionis (Zam et al. 1971). H. delamurei had only been reported in long-finned pilot whales Globicephala melas in the Western Mediterranean and NE Atlantic (Raga \& Balbuena 1993). Our specimens differ from those of pilot whales in that they have a longer cirrus sac, and a smaller acetabulum and testes, but we consider these differences to result from intraspecific variation.

Adult specimens of the cestode Trigonocotyle globicephalae were found in 4 dolphins. One dolphin harboured 7 worms (4 in the first intestinal section and 3 in the second section), whereas 3 dolphins harboured single worms in the first intestinal section. Diagnostic traits of T. globicephalae have been controversial. Hoberg (1990) indicated that this species can be separated from congeneric species based on a combination of traits of the scolex, the testes and the cirrus sac that was confirmed in all our specimens. T. globicephalae has been reported previously in a Risso's dolphin from Japanese waters (Kikuchi et al. 1988). The only additional reported hosts for this species are pilot whales Globicephala spp. (see references in Raga 1994). In the Western Mediterranean, T. globicephalae is known to occur in long-finned pilot whales G. melas (Raga \& Balbuena 1993).

Metacestodes of tetraphyllideans, collectively named as Scolex pleuronectis (see Skrjabin 1972), were found in 13 dolphins. All larvae had a scolex with 4 monocular bothridia with an accessory sucker. However, 2 types were distinguished according to body size and habitat differences. 'Small' plerocercoids were found free along the intestine, but especially in the mucosa of the terminal colon and rectum (rarely other parts of the intestine and the mucosa of pyloric stomach). 'Large' plerocercoids were found free in hepatopancreatic ducts and the intestine, but particularly in anal crypts. The total number of worms could not be determined precisely because the worms inside the gut wall were particularly difficult to detect and withdraw from the tissue. A crude estimation indicated a range of 10 to several hundred individuals. The 2 types of $S$. pleuronectis observed in the present study have been reported, in the same microhabitats, in other cetaceans from the Western Mediterranean (Aznar et al. 1994, Agustí et al. 2000a). Following a seminal paper by Skrjabin (1972), several authors (Aznar et al. 1994, Agustí et al. 2000a) speculated that small and large S. pleuronectis could be less developed stages of Phyllobothrium and/or Monorygma, 
which are tetraphyllidean larvae that encyst in the blubber and mesenteries, respectively, of the anogenital area of most odontocete species worldwide (see references in Raga 1994). The main occurrence of $S$. pleuronectis in the terminal colon and anus suggests that these could be the sites whereby the worms would reach the ano-genital area. However, there is not yet definitive genetic and morphological evidence supporting the relationship between $S$. pleuronectis and the other metacestodes. There are very few reports of S. pleuronectis in cetaceans (see, e.g. Skrjabin 1972, Aznar et al. 1994, McAlpine et al. 1997, Agustí et al. 2000a). In Risso's dolphin, the only previous report is that of Stossich (1898) in the rectum of 1 individual. It is likely that $S$. pleuronectis is ubiquitous but has been overlooked because of its small size (1 to $4 \mathrm{~mm}$ ) and its main occurrence inside the gut wall. Raga \& Carbonell (1985), for instance, did not find $S$. pleuronectis in striped dolphins Stenella coeruleoalba from the Western Mediterranean. However, when the gut wall was carefully examined, S. pleuronectis was detected with a high prevalence (Raga et al. 1992, Aznar et al. 1994, Agustí et al. 2000b).

Three parasite species were found in single dolphins. A cyst of Pholeter gastrophilus (diameter: $9 \mathrm{~mm}$ ) was observed in the main stomach. The cyst contained a great amount of eggs but no worms. Howard et al. (1983) reported a similar observation in other cetacean species, suggesting that individuals of $P$. gastrophilus may leave the cyst and enter the stomach. It is also possible, however, that worms simply die and disintegrate within the cyst. In the only previous record of $P$. gastrophilus in a Risso's dolphin from Florida, Zam et al. (1971) reported the parasite in the wall of the abdominal cavity of the urogenital region. This location is exceptional because $P$. gastrophilus typically invades the submucosa of the stomach, and rarely that of the intestine (e.g. Dollfus 1973/74, Aznar et al. 1992). Perhaps Zam et al. (1971) misnamed Monorygma grimaldii as $P$. gastrophilus; the former usually encysts in the abdominal cavity around the urogenital region (see above). In any event, the record of $P$. gastrophilus in Risso's dolphins is not unusual because it is a generalist parasite of delphinids (Aznar et al. 1992, Raga 1994, and references therein), and has been found in other dolphins from the Western Mediterranean (Raga et al. 1992, Raga \& Balbuena 1993).

A single adult specimen of Tetrabothrius forsteri was found in the second intestinal section of 1 dolphin. There is 1 previous record of an unidentified species of Tetrabothrius in a Risso's dolphin from Alaska (Shults et al. 1982). T. forsteri has been reported worldwide in many odontocetes, especially delphinids (see, e.g. Raga 1994 and references therein). In the Western Mediterranean, it occurs fre- quently in striped dolphins (Raga et al. 1992, Agustí et al. 2000b), but has not been found in pilot whales (Raga \& Balbuena 1993).

Finally, 2 individuals of Stenurus globicephalae were found in the intestine of 1 dolphin. This site of infection can be considered as accidental because S. globicephalae typically occurs in the air sinuses and the tympanic cavity of odontocetes (references in Raga 1994). Geraci et al. (1978) made similar observations in the alimentary tract of white-sided dolphins Lagenorhynchus acutus, suggesting that the parasites, which were very abundant in the head sinuses, may have been swallowed accidentally.

Some crater-like ulcers, superficially similar to those provoked by the nematode Anisakis simplex (see Smith 1989), were observed in the forestomach of 3 dolphins. However, no worms were found and, therefore, the origin of the ulcers is unclear.

The intestinal helminth communities of Risso's dolphin are species-poor (4 species at the component community level including Scolex pleuronectis; mean no. of species per host \pm SD: $1.12 \pm 1.09$ ), as it might be expected for cetaceans (see Aznar et al. 2001). In addition, parasite prevalences were low $(<50 \%)$, and intensities were very low, except for $S$. pleuronectis. It has been suggested that oceanic cetaceans would generally have a low probability of being infected because of the 'dilution' effect of infective stages in this habitat (Hoberg 1996, Raga et al. 2002). Regarding helminth fauna composition, all parasite species found in Risso's dolphins also occur in other oceanic cetaceans from the Western Mediterranean, i.e. striped dolphins and/or long-finned pilot whales (Raga et al. 1992, Raga \& Balbuena 1993). However, the most prevalent species that occur as adults, Hadwenius delamurei and Trigonocotyle globicephalae, are only shared with pilot whales (see references above). This pattern of specificity likely reflects the diet similarity and phylogenetic closeness between Risso's dolphins and pilot whales (see LeDuc 2002).

Acknowledgements. We are very grateful to E. Ferrer for invaluable help with examination of viscera. Thanks are due to Drs. A. Kostadinova and J. A. Balbuena for their help in identification of worms. We also want to thank the colleagues who helped in the necropsies of animals. Cetaceans were collected thanks to the agreement between the Conselleria de Medio Ambiente (Generalitat Valenciana) and the University of Valencia. F.J.A. benefits from a 'Ramón y Cajal' contract from the MCYT of Spain.

\section{LITERATURE CITED}

Abollo E, López A, Gestal C, Benavente P, Pascual S (1998) Macroparasites in cetaceans stranded on the northwestern Spanish Atlantic coast. Dis Aquat Org 32:227-231

Agustí C, Aznar FJ, Raga JA (2000a) New data about Tetra- 
phyllidean larvae (Cestoda) in Mediterranean dolphins. Acta Parasitol 45:168

Agustí C, Aznar FJ, Raga JA (2000b) Structure of intestinal helminth communities of Stenella coeruleoalba from the western Mediterranean. Eur Res Cetacean 14:261

Aznar FJ, Fernández M, Balbuena JA, Raga JA (1992) Patterns of colonization of Pholeter gastrophilus in Stenella coeruleoalba and Phocoena phocoena. Eur Res Cetacean 6:214-217

Aznar FJ, Balbuena JA, Raga JA (1994) On the identity and emigration of Scolex pleuronectis larvae (Cestoda) in the striped dolphin. Eur Res Cetacean 8:243-246

Aznar FJ, Balbuena JA, Bush AO, Raga JA (1997) Ontogenetic habitat selection of Hadwenius pontoporiae (Digenea) in the intestine of franciscana (Pontoporia blainvillei) (Cetacea). J Parasitol 83:13-18

Aznar FJ, Balbuena JA, Fernández M, Raga JA (2001) Living together: the parasites of marine mammals. In: Evans PGH, Raga JA (eds) Marine mammals. Biology and conservation. Kluwer Academic/Plenum Publishers, New York, p 385-423

Baird RW (2002) Risso's dolphin, Grampus griseus. In: Perrin WF, Würsing B, Thewissen HGM (eds). Encyclopedia of marine mammals. Academic Press, San Diego, p 1037-1039

Bush AO, Lafferty KD, Lotz JM, Shostak AW (1997) Parasitology meets ecology in its own terms: Margolis et al. revisited. J Parasitol 83:575-583

Dailey M, Stroud R (1978) Parasites and associated pathology observed in cetaceans stranded along the Oregon coast. J Wildl Dis 14:503-511

Dollfus R Ph (1973/74) Pholeter (Trematoda Digenea) from an intestinal cyst of Stenella coeruleoalba Meyen, 1833 (Odontoceti Delphinidae). Comments on the family Pholeteridae, R. Ph. Dollfus, 1939. List of helminths identified to date in Stenella coeruleoalba Meyen. Invest Cetacean 5: 331-337

Georgiev B, Biseerkov V, Genov T (1986) In toto staining method for cestodes with iron acetocarmine. Helminthologia 23:279-281

Geraci JR, Lounsbury VJ (1993) Marine mammals ashore. A field guide for strandings. Texas A\&M University Sea Grant College Program, Galveston

Geraci JR, Testaverde SA, St Aubin DJ, Loop H (1978) A mass stranding of the Atlantic white-sided dolphin, Lagenorhynchus acutus: a study into pathobiology and life history. Final Report, Marine Mammal Commission, Washington, DC, p 1-141

Hoberg EP (1990) Trigonocotyle sexitesticulae sp. nov. (Eucestoda: Tetrabothriidae): a parasite of pygmy killer whales (Feresa attenuata). Can J Zool 68:1835-1838

Hoberg EP (1996) Faunal diversity among avian parasite assemblages: the interaction of history, ecology and biogeography in marine systems. Bull Scand Soc Parasitol 6: 65-89

Howard EB, Britt JO Jr, Matsumoto GK, Itahara R, Nagano

Editorial responsibility: Murray Dailey,

Sausalito, California, USA
CN (1983) Parasitic diseases. In: Edward BH (ed) Pathobiology of marine mammal diseases, Vol I. CRC Press, Boca Raton, FL, p 119-232

Kikuchi S, Okuyama Y, Nakajama M (1988) Morphology of a tapeworm Trigonocotyle lintoni Guiart, 1935 from a Grampus griseus. Jpn J Parasitol 37:19-20

LeDuc R (2002) Delphinids, overview. In: Perrin WF, Würsing B, Thewissen HGM (eds) Encyclopedia of marine mammals. Academic Press, San Diego, p 310-314

McAlpine DF, Murison LD, Hoberg EP (1997) New records for the pygmy sperm whale, Kogia breviceps (Physeteridae) from Atlantic Canada with notes on diet and parasites. Mar Mamm Sci 13:701-704

Mignucci-Giannoni M, Hoberg EP, Siegel-Causey D, Williams EH Jr (1998) Metazoan parasites and other symbionts of cetaceans in the Caribbean. J Parasitol 84: 939-946

Raga JA (1994) Parasitismus bei Cetacea. In: Robineau D, Duguy $R$, Klima $M$ (eds) Handbuch der Säugetiere Europas. Bd. 6/1A. Aula-Verlag, Wiesbaden, p 132-179

Raga JA, Balbuena JA (1993) Parasites of the long-finned pilot whale, Globicephala melas (Traill, 1809), in European Waters. In: Donovan GP, Lockyer $\mathrm{CH}$, Martin AR (eds) Biology of Northern Hemisphere pilot whales. Rep Int Whal Comm Spec Issue 14:391-406

Raga JA, Carbonell E (1985) New dates about parasites on Stenella coeruleoalba (Meyen, 1833) (Cetacea: Delphinidae) in the western Mediterranean sea. Invest Cetacean $17: 207-213$

Raga JA, Aznar FJ, Balbuena JA, Fernández M (1992) Parasites and epizoits in striped dolphins affected by an epizootic in western Mediterranean. In: Pastor X, Simmonds M (eds) Proc Mediterranean Striped Dolphins Mortality International Workshop. Greenpeace International Mediterranean Project, Madrid, p 39-46

Raga JA, Aznar FJ, Balbuena JA, Fernández M (2002) Parasites. In: Perrin WF, Würsing B, Thewissen HGM (eds) Encyclopedia of marine mammals. Academic Press, San Diego, p 867-876

Shults LM, Fay FH, Hall JD (1982) Helminths from Stejneger's beaked whale Mesoplodon stejnegeri and Risso's dolphin Grampus griseus in Alaska. Proc Helminthol Soc Wash 49: 146-147

Skrjabin AS (1972) Larvae of cestodes of the genus Phyllobothrium Beneden, 1850 (Tetraphyllidae), parasites of whales and other marine mammals. Parazitologiia 6: 426-434

Smith JW (1989) Ulcers associated with larval Anisakis simplex B (Nematoda: Ascaridoidea) in the forestomach of harbour porpoises Phocoena phocoena. Can J Zool 67: $2270-2276$

Stossich M (1898) Note parassitologiche. Boll Soc Adriatica Sci Nat Trieste XVIII:1-10

Zam SG, Caldwell DK, Caldwell, MC (1971) Some endoparasites from small odontocete cetaceans collected in Florida and Georgia. Cetology 2:1-11

Submitted: January 21, 2003; Accepted: March 12, 2003

Proofs received from author(s): May 5, 2003 